Research, part of a Special Feature on Advancing the Understanding of Behavior in Social-Ecological Systems: Results from Lab and Field Experiments

\title{
Sharing as risk pooling in a social dilemma experiment
}

\author{
Todd L. Cherry ${ }^{1,2}$, E. Lance Howe ${ }^{3}$ and James J. Murphy ${ }^{3,4,5}$
}

\begin{abstract}
In rural economies with missing or incomplete markets, idiosyncratic risk is frequently pooled through informal networks. Idiosyncratic shocks, however, are not limited to private goods but can also restrict an individual from partaking in or benefiting from a collective activity. In these situations, a group must decide whether to provide insurance to the affected member. We describe results of a laboratory experiment designed to test whether a simple sharing institution can sustain risk pooling in a social dilemma with idiosyncratic risk. We tested whether risk could be pooled without a commitment device and, separately, whether effective risk pooling induced greater cooperation in the social dilemma. We found that even in the absence of a commitment device or reputational considerations, subjects voluntarily pooled risk, thereby reducing variance in individual earnings. In spite of effective risk pooling, however, cooperation in the social dilemma was unaffected.
\end{abstract}

Key Words: collective action; experimental economics; idiosyncratic risk; income smoothing; insurance; lab experiment; public goods; resource sharing; risk pooling; social dilemma; social-ecological systems; team production

\section{INTRODUCTION}

Subsistence communities in low-income and high-income countries alike rely on the yields of natural resources that are susceptible to both covariate shocks such as droughts or floods, which impact an entire community, and idiosyncratic shocks such as illness, injury, or disabled equipment, which impact an individual within a community. Although incomplete insurance and credit markets limit the ability of households to insure against risk, meaningful risk sharing or risk pooling does arise through informal mechanisms both within and across communities. Covariate shocks are difficult to insure locally, but idiosyncratic risk can often be pooled within communities. A variety of informal risk-sharing mechanisms have been documented in remote rural communities around the world, including gift giving, food sharing, remittances, rotating savings, and unstructured loans (Fafchamps 2003). These risk-pooling arrangements are facilitated through a transfer of resources among group members, and therefore also can be referred to as resource pooling or resource sharing. We describe results from a laboratory experiment designed to test the conditions under which idiosyncratic risk is pooled. We focus on idiosyncratic risk and voluntary sharing within a social dilemma, which is representative of many types of activities in a rural context.

A growing body of literature within development economics explores the theoretical and empirical dimensions of risk-sharing arrangements that protect against idiosyncratic risk. Research has found that a large share of intra-village risk is pooled, and standard theory suggests that self-enforcing agreements, under which an individual's gain from defection is less than the longterm benefits of cooperation, are critical to the success of these risk-sharing networks (Posner 1980, Kimball 1988, Fafchamps and Lund 2003, Genicot and Ray 2003, De Weerdt and Dercon 2006, Fafchamps and Gubert 2007). Under full insurance, a commitment device must be strong enough, e.g., through heavy punishment or a legal option, to maintain self-enforcing agreements, creating a risk-pooling network that is immune from individual defection. With only limited commitment, however, theory predicts only partial risk sharing and less than full insurance (Posner 1980, Kimball 1988, Ligon et al. 2002). Evidence from empirical studies is generally consistent with limited-commitment models because a high degree of partial consumption smoothing is often observed; however, informal mechanisms, including risk sharing, fail to provide full insurance (e.g., Townsend 1994, Udry 1994, Jalan and Ravallion 1999, Ligon et al. 2002, Fafchamps and Gubert 2007).

These and other efforts have contributed to the understanding of informal risk sharing and its ability to insure against shocks to private assets and income, but shocks are not limited to private goods. In remote rural communities with active risk-pooling networks, productive activities are often done collectively. In hunter-gatherer societies, for instance, participation in collective activities and the associated food sharing have been well documented (Kaplan et al. 1985). Indeed, there is archeological and ethnographic evidence indicating a long history of publicgood provision in foraging communities (Hawkes 1993). Likewise, in the collective agrarian arrangements in West Africa, output is pooled and distributed among members of the collective as needed (West 2010). An individual's ability to participate in, or to receive the benefits from, collective action can be affected by idiosyncratic shocks such as illness or mechanical problems, and the group must decide whether to provide insurance through sharing.

The specific example that motivated our research design was the collective hunting and gathering activities observed in the remote rural mixed economies of the Russian Far East and Alaska. In these remote regions, where standard measures of income poverty are extreme, wild foods or "subsistence" comprise a significant share of the diet. In the relatively isolated communities within these regions, individuals belong to distinct networks that harvest greens, berries, fish, and mammals. Food collectively obtained is then distributed to individuals within the network (Magdanz et al. 2002, Argetsinger and West 2009, Gerkey 2010). Salmon fishing in Western Alaska and Kamchatka Russia, for instance, is primarily done in extended groups, often families, in which individuals contribute labor, gear, and cash to harvest and process fish. Individual members contribute not only to the harvesting,

\footnotetext{
${ }^{1}$ Appalachian State University, ${ }^{2}$ Center for International Climate and Environmental Research (CICERO), ${ }^{3}$ University of Alaska Anchorage, ${ }^{4}$ Nankai University, ${ }^{5}$ Chapman University
} 
processing, and distribution of the catch but also to the extensive preparation for the harvest season, e.g., repairing nets, boats, and fish camp infrastructure.

It is not uncommon for a network member contributing equipment, cash, or labor in preparation for the harvest to be unable to participate in harvesting or processing because of illness, injury, or other unforeseen circumstance. Similarly, because salmon is dried on fish racks and stored in elevated platforms, animals sometimes enter camp and destroy a household's store of harvested food. These events are independent of shock to a private activity such as a wage-paying job. Finally, although not the primary focus of this study, the yield from harvesting subsistence resources is stochastic, and as a result some groups may be more successful than others. In such cases, as in other remote regions, other community members must decide how much of the collective catch should be allocated to other community members (Fienup-Riordan 1986).

These idiosyncratic shocks to a collective, i.e., group, activity in these communities are independent of a shock to a private activity, and motivated the shock treatments in our experimental design. That is, the return on investment to the private activity is certain, whereas environmental risk is added to existing strategic risk in the group activity. As with private goods, the idiosyncratic shock introduces risk to individuals that can be pooled over the group. But, unlike private goods, a shock within a social dilemma can affect the aggregate level of resources available to the group. Because idiosyncratic shocks can affect a member's ability to contribute to the production of group benefits, it complicates the strategic environment of the collective action and potentially undermines cooperation by all members. For example, when other group members observe low levels of participation in the group activity, it may be difficult to discern whether this is because of free riding or a negative shock such as illness. Historical evidence suggests that shirking via feigned illness may have been common in the early American colonies and resulted in widespread food shortages (Bradford 2006).

However, when idiosyncratic risk exists within a social dilemma, voluntary risk sharing can not only smooth individual income levels, but also can maintain cooperation by reducing or eliminating the riskiness of the group activity. Questions arise about whether groups can effectively pool risk to smooth income when the income is derived from group resources, and whether sharing can overcome the adverse effects of risk on the collective production of those resources.

We used a series of lab experiments to focus on the sharing of idiosyncratic risk in a social dilemma setting. Although our design uniquely addressed idiosyncratic risk within a social dilemma, several related studies were consistent with some features of our design. Charness and Genicot (2009) and Selton and Ockenfels (1998) explored risk sharing in a two-player solidarity game in which one player randomly received a positive shock in each round and each player was allowed to "share" with the other player. Charness and Genicot (2009) found strong evidence for risk sharing, or solidarity, in the absence of an explicit commitment device and noted that increasing the potential for direct reciprocity significantly increased risk pooling. Barr and Genicot (2008) and Attanasio et al. (2012) tested the effects of different levels of commitment in a game in which individuals could pooled outcomes from a risky gamble. Risk in their study, however, was not explicitly idiosyncratic or exogenous. They varied levels of commitment and found that limiting commitment reduced the frequency with which individuals pool earnings from the gamble. Kaplan et al. (2012) used a series of laboratory experiments to test whether resource sharing could be explained by risk-sharing motivations versus other alternatives. They found strong evidence for risk-pooling motivations. When subjects individually harvested from a highly variable resource, they were more likely to form reciprocal sharing relationships compared with harvesting from low risk environments. Finally, Erkal et al. (2011) explored the effects of relative earnings on giving decisions, with earnings based on a tournament-style real effort activity. Although not the focus of their study, they found that players receiving a negative shock also received large and significant transfers from other players.

There is also a large experimental literature that focuses on covariate, or aggregate, risk in a social dilemma. Much of this research focuses on a common pool resource environment and generally finds that increased environmental uncertainty leads to lower levels of cooperation (see Gangadharan and Nemes 2009 for a review). Of these, the most closely related to our study is Gangadharan and Nemes 2009, who introduced an aggregate shock into a public-goods game. Treatments varied according to whether this shock was associated with the private or the public good, and whether the probability distribution was known, i.e., risk, or unknown, i.e., uncertainty. They found that individuals avoided investing in a risky private account, preferring the strategic uncertainty associated with the group account. However, when the group account faced a possible shock, and therefore included both environmental and strategic uncertainty, cooperation dropped significantly.

In the Arctic and sub-Arctic regions that motivated our study, particularly in Alaska, the scale of harvest by subsistence users is a small percentage of the total harvest. For example, in the Kuskokwim salmon fishery, subsistence accounted for $21 \%$ of the total catch between 1980 and 2004. Commercial fisheries are responsible for the bulk of the salmon harvests: approximately $78 \%$ during this same period (Howe and Martin 2009). With other resources such as marine mammals, harvest quotas are strictly enforced. Moreover, because these communities do not have access to commercial markets, and because harvesting entails significant effort and financial costs, the incentives to overharvest the resource are quite weak. As a result, the key questions for these communities focus on cooperation in jointly harvesting the resource and sharing the fruits of the harvest. This is, in effect, a team production problem for which the linear public-goods game is a reasonable approach (Alchian and Demsetz 1972, Croson 2001, Carpenter et al. 2009).

Our team production experiments varied a standard linear publicgoods game in which we introduced the potential for a negative idiosyncratic shock. The shock eliminated the individual's allocations to, and returns from, the group activity. In some treatments, individuals were given an opportunity to share with the fellow group member who incurred the shock. Because individuals could avoid the shock by shifting resources from the group activity to the private activity, we decomposed the welfare loss into two components: the direct loss due to the shock and the indirect loss due to changes in cooperative behavior. 
Table 1. Experimental design.

\begin{tabular}{lll}
\hline \hline Treatment & Features & Summary \\
\hline Baseline & Baseline & Standard VCM \\
Shock & Baseline + Shock & Add idiosyncratic shock \\
Without Commitment & Baseline + Shock + Sharing & Simultaneously make allocation and sharing decisions. \\
With Commitment & Baseline + Shock + Sharing & Make sharing decision. Aggregate sharing announced. Make allocation \\
& & decision. \\
\hline
\end{tabular}

Compared with existing experimental research on risk pooling, our study differed along the commitment dimension, the nature of the shock, and the strategic environment. Like Charness and Genicot (2009), we introduced sharing without commitment, but in contrast to their study, we eliminated all opportunities for individual reciprocity. In addition, we added a treatment that tests whether perfectly enforced sharing commitments affect decisions about the level of participation in the group activity. Several experimental studies of risk pooling focused on the sharing of gains from a lottery (Barr and Genicot 2008, Attanasio et al. 2012), but very few (Erkal et al. 2011, Kaplan et al. 2012) allowed subjects to pool negative shocks through sharing or some other mechanism. Finally, we are unaware of any studies that investigated the pooling of idiosyncratic risk in a social dilemma and the resulting effects on cooperation.

Our results suggest that risk not only increased the variability of individual earnings, but also induced significant earnings losses due to less cooperative behavior. Contrary to theory, however, we found significant levels of risk pooling without commitment and without the possibility for direct reciprocity. Surprisingly, although individuals did cooperate in pooling risk, high levels of sharing commitments appeared to have no effect on cooperation in the social dilemma. As a result, there was less variation in income but no improvement in aggregate welfare in the treatments with a shock and the opportunity for sharing.

\section{EXPERIMENTAL DESIGN}

To investigate the impact of idiosyncratic risk in a social dilemma and the elements of risk-sharing arrangements that might mitigate any adverse effects, we constructed a set of four treatments (see Table 1): a Baseline treatment to provide a clear internal and external benchmark, a Shock treatment that introduced idiosyncratic risk and shed light on the impact of risk in a social dilemma, and two sharing treatments that varied levels of sharing commitment

\section{Baseline treatment}

The Baseline treatment was a standard linear public-goods game in which individual earnings are $\pi_{i}=\left(e-x_{i}\right)+(m / n) \Sigma_{\mathrm{i}} \mathrm{x}_{i}$, in which $e=20$ is the initial resource endowment, $x_{i}$ is the amount of resources individual $i$ allocates to the group activity, $m=2$ is the multiplier on the aggregate amount of resources allocated to the group activity, and $n=5$ is the number of subjects in a group. The marginal per capita return (MPCR) from the group activity is $\mathrm{m} /$ $n=0.40$. These parameters are identical in all four treatments. After all subjects completed their allocation decisions, the results were announced. Subjects received information about their own resource allocation decisions and earnings. Subjects were also informed about the aggregate amount of resources allocated to the group activity, but the individual decisions of the other four group members were not revealed. Although standard theory predicts that nothing will be allocated to the group activity, experimental evidence consistently shows positive, though less than socially optimal, allocations that decline over time (Ledyard 1995). We expected to observe this well-documented behavior in the Baseline treatment.

\section{Shock treatment}

The Shock treatment paralleled the Baseline treatment, but introduced idiosyncratic risk by randomly selecting one group member to receive a negative shock after all allocation decisions were made. The idiosyncratic shock resulted in the entire loss of the individual's allocation to the group activity, but had no impact on the individual's allocation to his private activity. In addition, the shock prevented the individual from receiving any returns from the group activity. Instead, the group returns were equally distributed among the remaining $n-1$ group members who did not receive the shock. This structure was meant to parallel the types of shocks described in the Introduction, such as the loss of one's harvest due to spoilage or an animal entering camp and destroying food stores.

The identity of the person shocked was not announced. Instead, group members were only informed about whether they are affected by the shock. Expected earnings in the shock treatment were $\pi_{i}=[(n-1) / n] \cdot\left[(m /(n-1)) \cdot \Sigma_{i}\left(x_{i}-x^{s}\right)+\left(e-x_{i}\right)\right]+(1 / n) \cdot$ $\left(e-x_{i}\right)$, with $x^{s}$ being the group allocation of the subject who incurred the shock. The expected MPCR remained unchanged at 0.40 .

The potential for a negative shock to eliminate an individual's return from the group activity introduced an additional disincentive to allocate resources to the group activity. In addition to the usual strategic risk that defines the collective action problem, group members also faced an environmental risk because of the potential idiosyncratic shock. More specifically, in the no-shock Baseline treatment, earnings from an individual's own allocation to the group activity were $(m / n) \cdot x_{i}>0$, whereas the Shock treatment introduced a $1 / n$ chance that these earnings would instead be zero. This implies that an individual who was predisposed toward cooperation and allocated the entire resource endowment to the group activity $\left(x_{i}=\mathrm{e}\right)$ risked earning nothing. Shifting resources from the group activity to the private activity avoided both the strategic and the environmental risk, and guaranteed that earnings would be at least $e$. Therefore, we expected to find that, relative to the no-shock Baseline treatment, the Shock treatment would have fewer resources allocated to the group activity, lower individual and group earnings, and greater variance in individual earnings. 
Fig. 1. Example of the subject interface for the Baseline treatment.

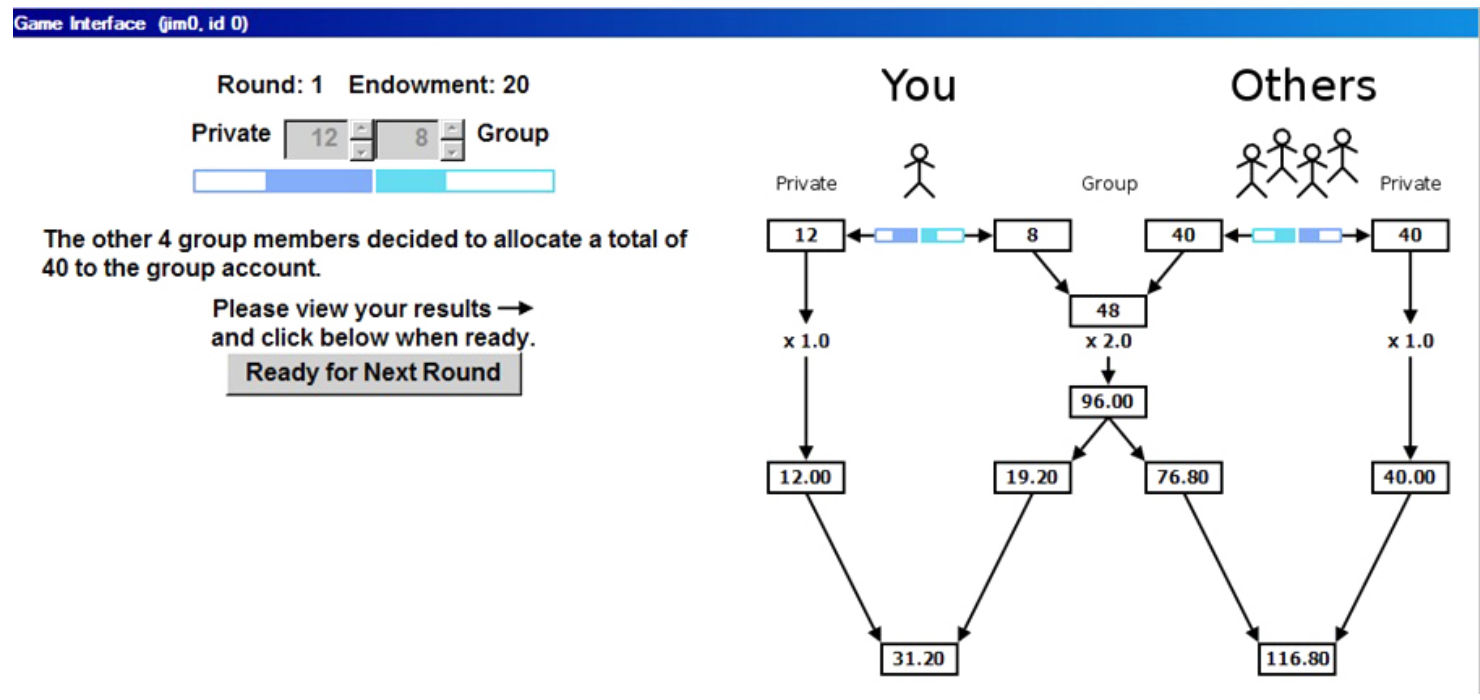

\section{Sharing treatments}

The remaining two treatments allowed the $n-1$ individuals who were unaffected by the shock to share a percentage of their returns from the group activity, $s_{i} \in[0 \%, 100 \%]$, with the individual who was shocked. The decision was framed as a percentage of the returns from the group account rather than a specific dollar amount, because the actual returns from the group account were unknown at the time the sharing decision was made. In both treatments, all agents made sharing decisions simultaneously without knowing the sharing decisions of other players. Treatments differed in whether a binding sharing commitment was made and disclosed to the group before the resource allocation decision. In both sharing treatments, expected individual earnings were as follows:

$\pi_{i}=[(n-1) / n] \cdot\left[\left(1-s_{i}\right) \cdot\left((m /(n-1)) \cdot \Sigma_{i}\left(x_{i}-x^{s}\right)\right)+\left(e-x_{i}\right)\right]+$ $(1 / n) \cdot\left[\left(e-x_{i}\right)+\Sigma_{j \neq i} \mathrm{~s}_{j} \cdot\left((m /(n-1)) \cdot \Sigma_{j \neq i} \mathrm{x}_{j}\right)\right]$.

In the Without Commitment treatment, all $n$ subjects simultaneously made both an allocation and a sharing decision. After all subjects submitted both decisions, results were announced. Subjects were informed of the aggregate amount of resources allocated to the group activity and the average sharing decision of the other $n-1$ group members, $[1 /(n-1)] \cdot \Sigma_{j \neq i} \mathbf{s}_{j}$, which represents the percentage of the returns from the group activity that would be shared with individual $i$ if he were shocked.

In the With Commitment treatment, each subject first committed to sharing a percentage of returns from the group activity, which were unknown at the time of the sharing decision. After all group members submitted their sharing decisions, the average sharing decision of other $n-1$ group members was announced. Each group member then submitted his allocation decision. Thus, before the allocation decision, each subject knew exactly what percentage of the group returns he would receive if shocked. This reduced the idiosyncratic environmental risk associated with the group activity and should have resulted in more resources allocated to the group activity relative to the Shock treatment.
Although each sharing mechanism provided an opportunity for group members to pool idiosyncratic risk, standard theory predicts no sharing in the absence of a commitment device. Although Charness and Genicot (2009) demonstrated the possibility for risk pooling without commitment, we went a step further in that our design removed the possibility for individual reciprocity. In both our sharing treatments, it was impossible for subjects to gain information about the individual allocation or sharing decisions of other players. We tested the null hypothesis of no sharing, but considering the substantial literature on cooperative behavior and partial risk pooling, we expected to observe at least some risk sharing, which would smooth income. Because sharing is just a redistribution of wealth, there was no impact on the group's aggregate earnings.

Sharing at least some of the returns from the group activity mitigated the adverse impacts of the idiosyncratic shock. As a result, if sharing was used as insurance, then these commitments should have increased allocations to the group activity. This implies that group allocations should be higher in the With Commitment treatment compared with the Without Commitment treatment. Also, if we observed nontrivial rates of sharing, we expected that relative to the Shock treatment, both sharing treatments would have more resources allocated to the group activity, greater individual and group earnings, and less variation in individual earnings.

\section{Experiment details}

Undergraduate students $(n=120)$ were recruited from the undergraduate student population at the University of Alaska Anchorage to participate in the experiment. All sessions were programmed and conducted using software developed specifically for this research project. The related code can be freely downloaded at $h \mathrm{ttp}: / /$ econlab.uaa.alaska.edu/Software.html. On entering the lab, participants signed a consent form acknowledging their voluntary participation and agreeing to abide by lab rules. The computerized instructions included both graphical and written explanations, and concluded with an interactive quiz that required correct responses before proceeding 
Table 2. Mean individual decisions and earnings.

\begin{tabular}{lcccccc}
\hline \hline & $\begin{array}{c}\text { Allocation to } \\
\text { Group Account }\end{array}$ & & \multicolumn{2}{c}{ Level of Earnings } & \multicolumn{2}{c}{$\begin{array}{c}\text { Mean Standard } \\
\text { Deviation of Earnings }\end{array}$} \\
\cline { 4 - 6 } Treatment & & Sharing & Not Shocked & Shocked & All & \\
\hline Baseline & 10.4 & - & -- & - & 30.4 & 5.39 \\
Shock & 7.0 & - & 27.0 & 12.9 & 24.2 & 7.18 \\
Without Commitment & 7.2 & $16 \%$ & 24.4 & 24.2 & 24.4 & 6.10 \\
With Commitment & 6.9 & $18 \%$ & 24.3 & 24.1 & 24.3 & 5.63 \\
\hline
\end{tabular}

to the decision environment. Experiment instructions can be viewed at http://econlab.uaa.alaska.edu/shocksharing/. The use of diagrams in the instructions was motivated by Eckel et al. 2010. Figure 1 shows an example of the subject computer screen from the Baseline treatment.

The 4 treatments were conducted over 12 sessions, with each treatment repeated in 3 sessions. In each session, 10 subjects were randomly divided into 2 groups of 5 and subjects remained in the same group for all $T=15$ rounds. There were a total of $\mathrm{N}=120$ unique subjects, and 24 unique groups evenly divided among the 4 treatments. We therefore collected a total of 360 group-level and 1800 individual-level observations. At the end of the session, subjects were called one at a time to be paid privately in cash. Lab dollars were converted to US dollars at $\$ 1$ per experiment token. Average individual cash earnings were $\$ 24.77(\sigma=\$ 0.64)$ plus an additional $\$ 5$ for showing up on time.

To avoid risk pooling over rounds, individual cash earnings were determined by a single randomly selected round. This design choice parallels the severity of naturally occurring shocks. For individuals living in subsistence-dependent communities, an idiosyncratic shock, e.g., the inability to harvest because of injury or the loss of an entire harvest because of animals or spoilage, can mean that one's survival depends on the largesse of the community. As in the experiment, people in these communities cannot self-insure against the risk. By paying one period, the experimental design mimicked this inability to self-insure.

\section{RESULTS}

\section{Aggregate results}

Figure 2 presents the mean individual allocation to the group activity over time by treatment. Table 2 complements the figure by providing summary statistics for all rounds combined. In the Baseline treatment, which established the benchmark earnings and group resource allocation levels without idiosyncratic risk or sharing, mean individual allocations to the group activity was 10.4 tokens ( $52 \%$ of the 20 -token initial endowment). Group allocations in the first round averaged 13.1 tokens $(65 \%)$, decaying to 7.0 tokens $(35 \%)$ in the final round. This general pattern of moderate levels of cooperation in the early rounds, which then decay over time, is typical in a standard public goods experiment.

When the environmental risk associated with the group activity was introduced in the Shock treatment, which did not allow sharing, people tended to redirect resources away from the risky group activity and into the safe private activity. On average, individual allocations to the group activity dropped by about onethird relative to the no-shock Baseline treatment. Average allocations to the group activity started at 8.8 tokens in round 1 ( $44 \%)$, decaying to 4.3 tokens $(21 \%)$ in round 15 . The average over all rounds was $7.0(35 \%)$. As a result, relative to the no-shock Baseline group, the mean earnings in the Shock treatment group were $20 \%$ lower (\$24.2 vs. \$30.4).

Fig. 2. Mean individual allocation to the group account.

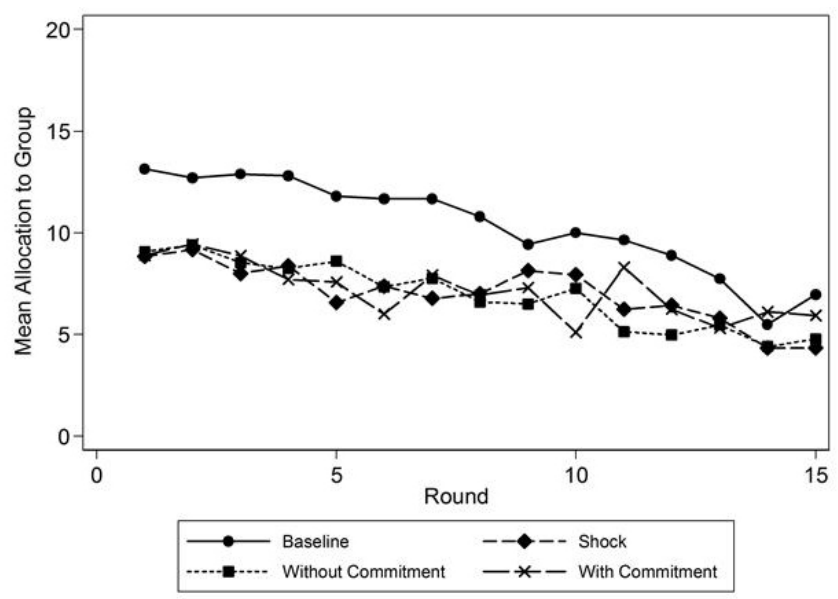

In Table 2, the average earnings in the Shock treatment group of those who were not shocked (\$27.0) were lower than those in the Baseline group (\$30.4) because of the reduced allocations to the group activity. This suggests that the presence of risk in the group activity had two effects on earnings: a direct effect due to the shock and an indirect effect due to changes in allocation behavior. We tested this by decomposing earnings into these two effects in Table 3. The column labeled "Before Shock, Before Sharing" reports individual earnings before the welfare loss from the shock and before income was redistributed through sharing. A comparison of the average earnings in the Shock and Baseline treatment groups reveals that changes in allocation behavior accounted for just more than half of the decline in earnings. Specifically, of the total difference in average earnings between the two treatments $(\$ 24.2-\$ 30.4=-\$ 6.2), 55 \%$ of the earnings loss occurred before the shock $(\$ 27.0-\$ 30.4=-\$ 3.4)$ because subjects shifted some tokens from the group activity to the private activity. The direct effect of the shock (from $\$ 27.0$ before the shock to $\$ 24.2$ after the shock) accounts for the other $45 \%$ of the loss in total earnings. Hence, the chilling indirect effect of idiosyncratic risk on cooperation is roughly equal to the direct earnings loss resulting from the shock. 
Table 3. Decomposition of earnings.

\begin{tabular}{|c|c|c|c|c|c|c|}
\hline & \multicolumn{3}{|c|}{ Average Earnings (all subjects) } & \multicolumn{3}{|c|}{ Mean Standard Deviation of Earnings } \\
\hline & $\begin{array}{c}\text { Before Shock } \\
\text { Before Sharing }\end{array}$ & $\begin{array}{c}\text { After Shock } \\
\text { Before Sharing }\end{array}$ & $\begin{array}{c}\text { After Shock } \\
\text { After Sharing }\end{array}$ & $\begin{array}{c}\text { Before Shock } \\
\text { Before Sharing }\end{array}$ & $\begin{array}{c}\text { After Shock } \\
\text { Before Sharing }\end{array}$ & $\begin{array}{c}\text { After Shock } \\
\text { After Sharing }\end{array}$ \\
\hline Baseline & 30.4 & -- & -- & 5.39 & -- & -- \\
\hline Shock & 27.0 & 24.2 & -- & 4.46 & 7.18 & -- \\
\hline Without Commitment & 27.2 & 24.4 & 24.4 & 4.37 & 7.47 & 6.10 \\
\hline With Commitment & 26.9 & 24.3 & 24.3 & 4.26 & 6.82 & 5.63 \\
\hline
\end{tabular}

The mean standard deviation of earnings is presented in Tables 2 and 3 and provides a measure of the average variability in an individual's earnings over time. The mean standard deviation of earnings $(s)$ was calculated as the mean of the individual withinsubject standard deviations $\left(\sigma_{i}\right)$, specifically: $s=(1 / N) \cdot \Sigma_{i} \sigma_{i}$, where $\sigma_{i}=[1 /(T-1)] \cdot \Sigma_{t}\left(\pi_{i t}-\Pi_{i}\right)^{2}$, and $\Pi_{i}=(1 / T) \cdot\left(\Sigma_{t} \pi_{i t}\right)$. By definition, the idiosyncratic shock introduced volatility to an individual's earnings over time. Average earnings were higher in those rounds when the individual was not shocked (\$27.0) than when he did incur the shock (\$12.9). As a result, the mean standard deviation in the Shock treatment group was higher than that in the Baseline group (\$7.18 vs. \$5.39). Before accounting for the shock, the mean standard deviation in the Shock treatment was actually lower than that in the Baseline group (\$4.46 vs. \$5.39). This follows from the reduction in resources allocated to the group activity in the Shock treatment. However, the negative direct effect of the shock dominated, leading to an overall increase in earnings variability. These results illustrate the additional complexity that arises when idiosyncratic risk exists within a social dilemma: not only does the shock have a direct impact on earnings, but it also has an indirect impact because individuals reduce their allocations to the group activity to lower their exposure to this environmental risk.

The two sharing treatments offered the potential to mitigate both the direct effects of the shock and the indirect effects of reduced allocations to the group activity. By sharing with other group members and mutually insuring against the environmental risk, it was possible to both increase earnings and reduce earnings variability compared with the Shock treatment. In each of the sharing treatments, fully insuring all group members against the idiosyncratic risk would require the individual sharing decisions to average $20 \%$ of the group returns $\left(s_{i}=0.20\right)$, but the standard game-theoretic prediction is that sharing will be nonexistent $\left(s_{i}=\right.$ 0.00). We did, however, observe considerable sharing in both treatments. Figure 3 shows that sharing began around full insurance in both treatments $(26 \%$ Without Commitment and $21 \%$ With Commitment), but declined over time to roughly $10 \%$ in each treatment.

This high level of sharing helped smooth incomes by mitigating the direct effects of the shock. If income smoothing were perfect, then individual earnings would be independent of the shock, and as a result, there would be no difference in average earnings between those who were shocked and those who were not. When the allocation and sharing decisions were made simultaneously in the Without Commitment treatment, it appears that income smoothing did occur at near-perfect levels. Figure 4 presents the difference in average earnings over time between those who were not shocked and those who were. In the Without Commitment treatment, this difference in any given round was modest; moreover, there were nearly as many rounds (6 of 15) in which the shock victims actually earned more than their benevolent counterparts. As a result, over all rounds, the average earnings of the two groups were nearly identical in this treatment (see Table 2).

Fig. 3. Mean individual percentage shared.

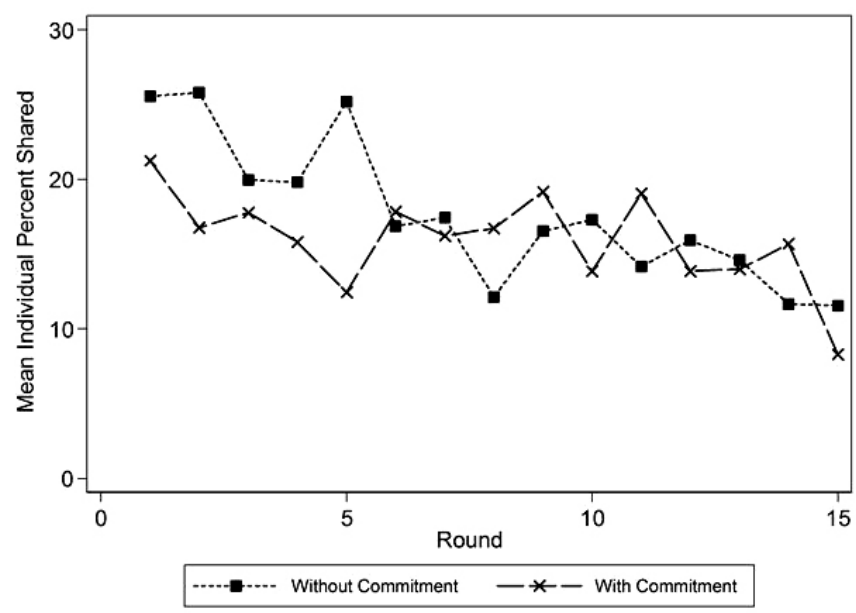

Fig. 4. Consumption smoothing (average earnings: not Shocked minus Shocked).

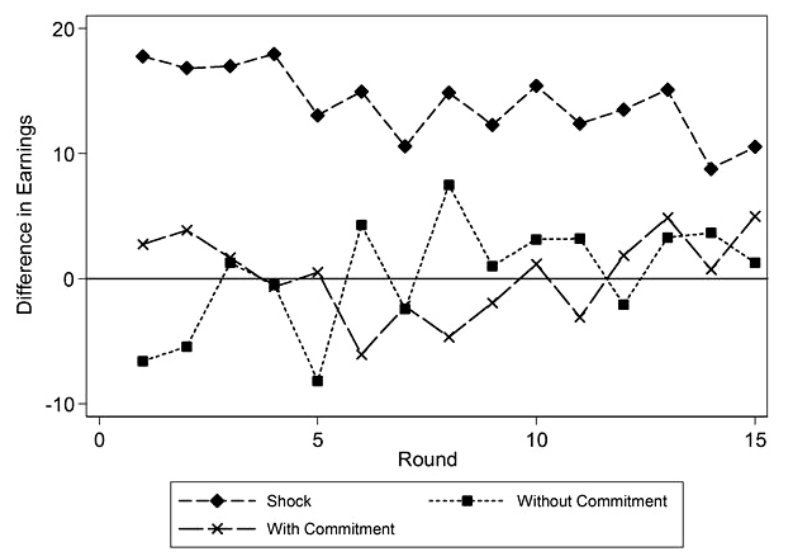


Table 4. Conditional estimates of individual-level treatment effects.

\begin{tabular}{|c|c|c|c|}
\hline & $\begin{array}{c}\text { Model 1: } \\
\text { Allocation to Group Account } \\
\left(x_{i t}\right)\end{array}$ & $\begin{array}{l}\text { Model 2: } \\
\text { Sharing } \\
\left(s_{i+}\right)\end{array}$ & $\begin{array}{c}\text { Model 3: } \\
\text { Earnings } \\
\left(\pi_{i+}\right)\end{array}$ \\
\hline Baseline Treatment & (omitted) & $\mathrm{n} / \mathrm{a}$ & (omitted) \\
\hline Shock Treatment & $\begin{array}{l}-3.36 \\
(0.00)\end{array}$ & $\mathrm{n} / \mathrm{a}$ & $\begin{array}{c}-6.19 \\
(0.00)\end{array}$ \\
\hline Without Commitment Treatment & $\begin{array}{l}-3.20 \\
(0.01)\end{array}$ & (omitted) & $\begin{array}{l}-5.99 \\
(0.00)\end{array}$ \\
\hline With Commitment Treatment & $\begin{array}{l}-3.44 \\
(0.00)\end{array}$ & $\begin{array}{c}0.017 \\
(0.573)\end{array}$ & $\begin{array}{l}-6.07 \\
(0.00)\end{array}$ \\
\hline Round & $\begin{array}{l}-0.34 \\
(0.00)\end{array}$ & $\begin{array}{l}-0.007 \\
(0.00)\end{array}$ & $\begin{array}{l}-0.27 \\
(0.00)\end{array}$ \\
\hline Intercept & $\begin{array}{l}13.10 \\
(0.00)\end{array}$ & $\begin{array}{l}0.212 \\
(0.00)\end{array}$ & $\begin{array}{l}32.49 \\
(0.00)\end{array}$ \\
\hline$x^{2}$ & $\begin{array}{l}73.89 \\
(0.00)\end{array}$ & $\begin{array}{l}29.23 \\
(0.00)\end{array}$ & $\begin{array}{l}60.57 \\
(0.00)\end{array}$ \\
\hline $\mathrm{N}$ & 1800 & 900 & 1800 \\
\hline
\end{tabular}

p-values in parentheses calculated using robust standard errors. In all three models, "omitted" means the data are included, but the treatment dummy variable is omitted. In the sharing model, " $\mathrm{n} / \mathrm{a}$ " means the data from the two treatments without sharing are not applicable and therefore not included.

Interestingly, although we did observe near-perfect income smoothing, it did not appear that this had any effect on the allocation of resources to the group activity. In fact, average allocations in the Without Commitment treatment (\$7.2) were about the same as those in the Shock treatment (\$7.0). As a result, average earnings in the two treatments were similar. This would suggest that, in the absence of prior commitments about how much risk will be covered by the group, the ability to share does reduce the riskiness of the group activity and reduce earnings fluctuations, but it has no impact on collective action. This outcome is certainly not consistent with prior expectations because it suggests that subjects view the sharing and resource allocation decisions independently. Although these data do not allow us to adequately test related hypotheses, this finding warrants future research.

The sequential nature of the With Commitment treatment introduced the ability to precommit to a sharing decision before making an allocation decision. With mean sharing around $18 \%$, the shock had a negligible effect on earnings: $\$ 24.3$ for those who were not shocked versus $\$ 24.1$ for those who did incur the shock. In fact, shock victims actually earned slightly more than the other group members in four of the first five rounds (see Fig. 4). However, despite perfect information about the generous sharing commitments, the average allocation to the group activity (\$6.9) was no different than that with the Shock (\$7.0) or Without Commitment (\$7.2) treatments. Therefore, it seems that high levels of income smoothing are possible with or without a sharing commitment mechanism, but sharing has no impact on cooperation in a social dilemma.

\section{Conditional results}

We confirmed our informal conclusions by using the more rigorous conditional analyses presented in Table 4 . We estimated three panel models that use the same basic structure: $Y_{i t}=\beta_{0}+$ $\beta_{1} \cdot \theta_{i t}+\beta_{2} \cdot t+\omega_{i}+\varepsilon_{i t}$, where $Y_{i t}$ is the individual allocation to the group activity (model 1), sharing (model 2), or earnings (model 3 ) of subject $i$ in round $t, \theta_{i t}$ is a set of treatment indicator variables that capture the treatment effects, $\omega_{i}$ captures unobserved individual subject characteristics, and $\varepsilon_{i t}$ represents the contemporaneous error term. Because subjects participated in multiple rounds of a single treatment, subject-specific heterogeneity was modeled as a random effect. We also used a Huber (1967) and White (1980) robust estimate of variance.

Consistent with the previous discussion of aggregate results, the allocation decision in model 1 reveals that the introduction of idiosyncratic risk in the Shock treatment significantly reduced allocations to the group activity relative to the Baseline treatment $(p=0.00)$. Surprisingly, the With Commitment and Without Commitment treatments had similar results. Both coefficients are negative and significant, and a Wald chi-square test failed to reject the joint hypothesis that group allocation decisions in the Without Commitment, With Commitment, and Shock treatments are equal ( $p=0.97)$. Results from the sharing model (model 2) also corroborate the aggregate findings. Individuals did exhibit significant levels of sharing in both sharing treatments. The coefficient for the intercept indicates average sharing in the Without Commitment treatment was $21 \%$, which is positive and significant. As expected, the coefficient on the With Commitment treatment is not significant, indicating that there was no difference in the sharing rates between the two treatments.

The earnings model in Table 4 (model 3) was not conditioned on whether an individual was shocked in a given round; therefore, it provides an estimate of an individual's expected earnings and is a measure of the relative welfare impacts among the different treatments. The earnings model indicates that, in the presence of an idiosyncratic shock, the expected individual earnings were lower than those in the no-shock Baseline group, i.e., all three treatment coefficients are negative and significant. More importantly, a joint test of the hypothesis that the three treatment coefficients are equal cannot be rejected $(p=0.98)$, which indicates that neither sharing treatment had a significant effect on expected earnings relative to the Shock treatment. 
Of course, individual earnings in a given round might have been affected by the shock, and the magnitude of this impact depended on the extent to which the other group members shared. Perfect smoothing implies that individual earnings are independent of the idiosyncratic shock (Mace 1991, Townsend 1994, Fafchamps and Lund 2003). To test the income-smoothing hypothesis, we modified the individual-earnings model in model 3 by adding three new explanatory variables that interact the treatments with an indicator variable (Shocked) that equals one if individual $i$ incurred the shock in round $t$ (Table 5 , model 4 ). Model 4 includes data only from the three treatments that included the idiosyncratic shock, and therefore does not include the Baseline treatment. The intercept can be interpreted as referencing the earnings of an individual who was not shocked in the Shock treatment group. The income-smoothing hypothesis implies that each of the three interaction coefficients should equal zero; i.e., for a given treatment, if the interaction term were zero, then we could not reject the hypothesis that individual earnings were independent of the shock.

Table 5. Conditional estimates of individual earnings.

\begin{tabular}{lc}
\hline \hline & $\begin{array}{c}\text { Model } 4: \\
\text { Earnings } \\
\left(\pi_{i}\right)\end{array}$ \\
\hline Shock Treatment & Omitted \\
Without Commitment Treatment & -2.48 \\
& $(0.01)$ \\
With Commitment Treatment & -2.62 \\
& $(0.00)$ \\
Shocked $\times$ & -13.70 \\
Shock Treatment & $(0.00)$ \\
Shocked $\times$ & -0.27 \\
Without Commitment Treatment & $(0.87)$ \\
Shocked $\times$ & -0.01 \\
With Commitment Treatment & $(0.99)$ \\
Round & -0.19 \\
& $(0.000)$ \\
Intercept & 28.42 \\
& $(0.000)$ \\
$\chi^{2}$ & 370.22 \\
& $(0.000)$ \\
N & 1350 \\
\hline
\end{tabular}

Model does not include Baseline treatment because it does not include a shock; p-values in parentheses calculated using robust standard errors.

Clearly, without the ability to share in the Shock treatment, the income-smoothing hypothesis was rejected. Individuals who were shocked earned \$13.7 less than those who were not shocked. In contrast, the results were consistent with the earnings-smoothing hypothesis in both the Without Commitment treatment ( $p=0.87$ ) and the With Commitment treatment $(p=0.99)$. In our environment, this simple sharing institution nearly eliminated the effects of idiosyncratic risk for the individual. Thus, the conditional results support the observations made using the aggregate results. Without sharing, an idiosyncratic shock had both a direct effect on the earnings of the shock victim and an indirect effect on the earnings of the entire group because of reduced allocation of resources to the group activity. The ability to share without any commitment mechanism did smooth individual earnings, but because group allocations were unchanged relative to the Shock treatment, the indirect effects of the shock persisted. As a result, average earnings were no greater than those without sharing. Group allocations, sharing, and earnings in the With Commitment treatment were statistically indistinguishable from those in the Without Commitment treatment.

\section{CONCLUSION}

We examined whether a sharing institution can facilitate risk pooling in a social dilemma with idiosyncratic risk. A standard public-goods game was augmented with a negative idiosyncratic shock and a simple sharing mechanism in which subjects made private, voluntary transfers to a fellow group member who was adversely affected by a shock. As predicted, environmental risk via the shock significantly reduced average earnings. This impact on earnings can be decomposed into two effects that are roughly equal in magnitude: the reduced earnings that were a direct consequence of the shock and the indirect effect due to behavioral changes to avoid the shock.

In contrast to basic theory, however, we found high levels of anonymous sharing in both sharing treatments. In both treatments, sharing completely removed the additional variance of individual earnings resulting from the shock, evidence consistent with the income-smoothing hypothesis. As such, risk pooling emerges without a strong self-enforcing agreement, an assumption needed in related theoretical models. This result is similar to that of Charness and Genicot (2009), but is stronger in that risk pooling was maintained even when the possibility for direct individual reciprocity was eliminated. Although nearperfect income smoothing was observed in the sharing treatments, collective action, measured in terms of the allocation of resources to the group activity, surprisingly did not improve with sharing.

This risk-pooling result is also consistent with ethnographic accounts of food sharing in Western Alaska and the Russian Far East (Gerkey 2010). Although no formal tests of consumption smoothing exist for Arctic communities, risk pooling is one explanation for the extensive food sharing observed in similar hunter-gatherer societies (Kaplan et al. 1985, 2012).

In conclusion, consistent with econometric results based on survey data from rural contexts, we found that subjects successfully pooled risk in an environment with idiosyncratic risk. Although sharing mechanisms have unique behavioral implications, we observed high levels of risk pooling without reputation or a strong commitment device.

\section{Responses to this article can be read online at: http://www.ecologyandsociety.org/issues/responses. $\mathrm{php} / 7390$}

\section{Acknowledgments: \\ Funding for the research was provided by the National Science Foundation (grant \#0729063). We wish to thank Ben Saylor for programming support and Dan Allen for research assistance.}




\section{LITERATURE CITED}

Alchian, A., and H. Demsetz. 1972. Production, information costs, and economic organization. American Economic Review 62 (5):777-795. http://dx.doi.org/10.1109/EMR.1975.4306431

Argetsinger, T., and C. West. 2009. Yupiit subsistence in Western Alaska: the intersection of formal and local institutions. Ecological and Environmental Anthropology 5(1):67-82.

Attanasio, O., A. Barr, J. C. Cardenas, G. Genicot, and C. Meghir. 2012. Risk pooling, risk preferences, and social networks. American Economic Journal: Applied Economics 4(2):134-167. http://dx.doi.org/10.1257/app.4.2.134

Barr, A., and G. Genicot. 2008. Risk sharing, commitment, and information: an experimental analysis. Journal of the European Economic Association 6(6):1151-1185. http://dx.doi.org/10.1162/ JEEA.2008.6.6.1151

Bradford, W. 2006. Of Plymouth Plantation, rendered into modern English with an introduction by Harold Paget. Dover, Mineola, New York, USA.

Carpenter, J., S. Bowles, H. Gintis, and S.-H. Hwang. 2009. Strong reciprocity and team production: theory and evidence. Journal of Economic Behavior \& Organization 71(2):221-232. http://dx.doi. org/10.1016/j.jebo.2009.03.011

Charness, G., and G. Genicot. 2009. Informal risk sharing in an infinite-horizon experiment. Economic Journal 119(537):796-825. http://dx.doi.org/10.1111/j.1468-0297.2009.02248.x

Croson, R. T. A. 2001. Feedback in voluntary contribution mechanisms: an experiment in team production. Pages 85-97 in R. M. and Isaac and D. A. Norton, editors. Research in experimental economics. Volume 8. Emerald Group, Bingley, UK. http://dx.doi.org/10.1016/S0193-2306(01)08005-X

De Weerdt, J., and S. Dercon. 2006. Risk-sharing networks and insurance against illness. Journal of Development Economics 81 (2):337-356. http://dx.doi.org/10.1016/j.jdeveco.2005.06.009

Erkal, N., L. Gangadharan, and N. Nikiforakis. 2011. Relative earnings and giving in a real-effort experiment. American Economic Review 101(7):3330-3348. http://dx.doi.org/10.1257/ $\underline{\text { aer.101.7.3330 }}$

Fafchamps, M. 2003. Rural poverty, risk, and development. Edward Elgar, Cheltenham, UK.

Fafchamps, M., and F. Gubert. 2007. The formation of risk sharing networks. Journal of Development Economics 83 (2):326-350. http://dx.doi.org/10.1016/j.jdeveco.2006.05.005

Fafchamps, M., and S. Lund. 2003. Risk-sharing networks in rural Philippines. Journal of Development Economics 71 (2):261-287. http://dx.doi.org/10.1016/S0304-3878(03)00029-4

Fienup-Riordan, A. 1986. When our bad season comes: a cultural account of subsistence harvesting and harvest disruption on the Yukon Delta. Alaska Anthropological Association, Anchorage, Alaska, USA.

Gangadharan, L., and V. Nemes. 2009. Experimental analysis of risk and uncertainty in provisioning private and public goods. Economic Inquiry 47(1):146-164. http://dx.doi.org/10.1111/ j.1465-7295.2007.00118.x
Genicot, G., and D. Ray. 2003. Group formation in risk-sharing arrangements. Review of Economic Studies 70(1):87-113. http:// dx.doi.org/10.1111/1467-937X.00238

Gerkey, A. 2010. From state collectives to local commons: cooperation and collective action among salmon fishers and reindeer herders in Kamchatka, Russia. Dissertation. Rutgers University, New Brunswick, New Jersey, USA.

Hawkes, K. 1993. Why hunter-gatherers work: an ancient version of the problem of public goods. Current Anthropology 34 (4):341-361. http://dx.doi.org/10.1086/204182

Howe, E. L., and S. Martin. 2009. Demographic change, economic conditions, and subsistence salmon harvests in Alaska's Arctic Yukon Kuskokwim region. Pages 433-462 in C. C. Krueger and C. E. Zimmerman, editors. Pacific salmon: ecology and management of western Alaska's populations. American Fisheries Society, Bethesda, Maryland, USA.

Huber, P. J. 1967. The behavior of maximum likelihood estimates under nonstandard conditions. Proceedings of the Fifth Berkeley Symposium on Mathematical Statistics and Probability 1 (1):221-233.

Jalan, J., and M. Ravallion. 1999. Are the poor less well-insured? Evidence on vulnerability to income risk in Rural China. Journal of Development Economics 58(1):61-81. http://dx.doi.org/10.1016/ $\underline{\text { S0304-3878(98)00103-5 }}$

Kaplan, H., K. Hill, R. V. Cadeliña, B. Hayden, D. C. Hyndman, R. J. Preston, E. A. Smith, D. E. Stuart, and D. R. Yesner. 1985. Food sharing among Ache foragers: tests of explanatory hypotheses. Current Anthropology 26(2):223-246. http://dx.doi. org/10.1086/203251

Kaplan, H. S., E. Schniter, V. L. Smith, and B. J. Wilson. 2012. Risk and the evolution of human exchange. Proceedings of the Royal Society B: Biological Sciences 279(1740):2930-2935. http:// dx.doi.org/10.1098/rspb.2011.2614

Kimball, M. 1988. Farmer cooperatives as behavior toward risk. American Economic Review 78(1):224-232.

Ledyard, J. 1995. Public goods: a survey of experimental research. Pages 111-194 in J. Kagel and A. Roth, editors. The handbook of experimental economics. Princeton University Press, Princeton, New Jersey, USA.

Ligon, E., J. P. Thomas, and T. Worrall. 2002. Informal insurance arrangements with limited commitment: theory and evidence from village economies. Review of Economic Studies 69 (1):209-244. http://dx.doi.org/10.1111/1467-937X.00204

Mace, B. J. 1991. Full insurance in the presence of aggregate uncertainty. Journal of Political Economy 99(5):928-956. http:// dx.doi.org/10.1086/261784

Magdanz, J. S., C. J. Utermohle, and R. J. Wolfe. 2002. The production and distribution of wild food in Wales and deering Alaska. Technical Paper 259. Division of Subsistence, Alaska Department of Fish and Game, Juneau, Alaska, USA. [online] URL: http://www.adfg.alaska.gov/techpap/tp259.pdf

Posner, R. A. 1980. A theory of primitive society, with special reference to law. Journal of Law and Economics 23(1):1-53. http:// dx.doi.org/10.1086/466951 
Selten, R., and A. Ockenfels. 1998. An experimental solidarity game. Journal of Economic Behavior \& Organization 34 (4):517-539. http://dx.doi.org/10.1016/S0167-2681(97)00107-8

Townsend, R. M. 1994. Risk and insurance in village India. Econometrica 62(3):539-591. http://dx.doi.org/10.2307/2951659

Udry, C. T. 1994. Risk and insurance in a rural credit market: an empirical investigation in Northern Nigeria. Review of Economic Studies 61(3):495-526. http://dx.doi.org/10.2307/2297901

West, C. T. 2010. Household extension and fragmentation: investigating the socio-environmental dynamics of Mossi domestic transitions. Human Ecology 38(3):363-376. http://dx. doi.org/10.1007/s10745-010-9317-3

White, H. 1980. A heteroskedasticity-consistent covariance matrix estimator and a direct test for heteroskedasticity. Econometrica 48(4):817-830. http://dx.doi.org/10.2307/1912934 